\title{
MODELS FOR \\ CLOSE-IN ATMOSPHERIC DISPERSION, EXPLOSIVE RELEASES, AND PARTICLE DEPOSITION
}

\author{
Sanford G. Bloom \\ System Safety Engineering
}

Date of Issue: October 6, 1993
OAK RIDGE NATIONAL LABORATORY
Oak Ridge, Tennessee 37831
managed by
Martin Marietta Energy Systems, Inc.
for the
U.S. DEPARTMENT OF ENERGY
under contract DE-AC05-84OR21400

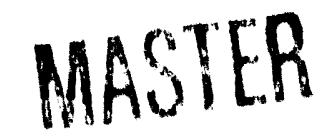


TABLE OF CONTENTS

PAGE

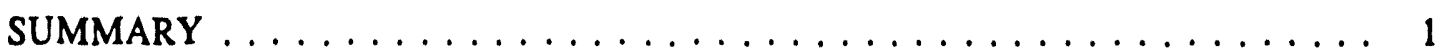

ATMOSPHERIC DISPERSION EQUATIONS $\ldots \ldots \ldots \ldots \ldots \ldots \ldots \ldots$

The Region Very Close To The Release (Less Then 2 Meters Down-wind) . . 1

The Region Beyond 2 Meters Down-wind for Large Sources $\left(r_{A}>0.04\right) \ldots .3$

The Region Beyond 2 Meters Down-wind for Small Sources $\left(r_{A} \leq 0.04\right) \ldots .3$

Recommended Dispersion Parameters $\ldots \ldots \ldots \ldots \ldots \ldots \ldots \ldots$

EXPLOSIVE RELEASES $\ldots \ldots \ldots \ldots \ldots \ldots \ldots \ldots \ldots \ldots \ldots$

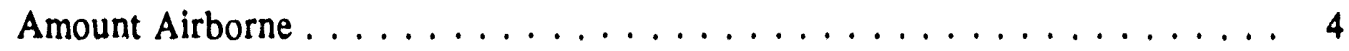

Particle-size Distribution of the Airborne Material $\ldots \ldots \ldots \ldots \ldots \ldots 4$

DISPERSION WITH PARTICLE DEPOSITION $\ldots \ldots \ldots \ldots \ldots \ldots \ldots, 5$

Time-weighted, Average Concentration $\ldots \ldots \ldots \ldots \ldots \ldots \ldots \ldots$

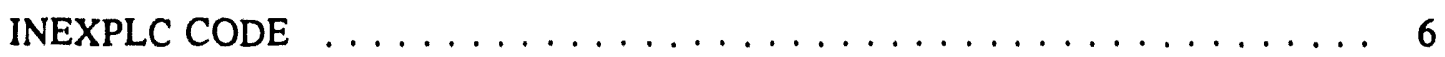

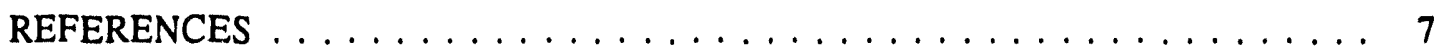

Appendix A. DERIVATION OF EQUATIONS FOR THE ATMOSPHERIC DISPERSION MODELS AND DEPOSITION MODELS

ATMOSPHERIC DISPERSION MODEL $\ldots \ldots \ldots \ldots \ldots \ldots$ A-1

DEPOSITION MODEL $\ldots \ldots \ldots \ldots \ldots \ldots \ldots \ldots \ldots \ldots$ A-3

Appendix B. LISTING OF SAMPLE INPUT, SAMPLE OUTPUT AND THE QUICKBASIC SOURCE FOR THE INEXPLC CODE

LISTING OF SAMPLE INPUT AND OUTPUT

FOR THE INEXPLC CODE $\ldots \ldots \ldots \ldots \ldots \ldots \ldots \ldots$ B-1

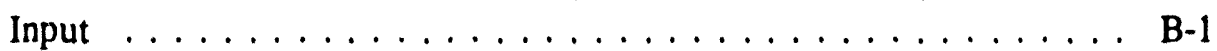

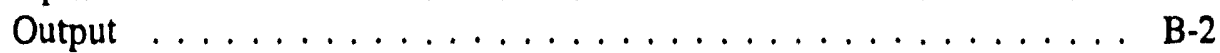

LISTING OF THE QUICKBASIC SOURCE

FOR THE INEXPLC CODE $\ldots \ldots \ldots \ldots \ldots \ldots \ldots \ldots$ B-3 


\section{SUMMARY}

Relatively simple models are presented to simulate close-in atmospheric dispersion, explosive releases, and particle deposition. Close-in generally refers to distances less than $50 \mathrm{~m}$ downwind from the source. These models assume simple gas dispersion (no chemical reactions, neutral buoyancy) and that particles behave as a gas except they can be removed from the plume by a simple, deposition-velocity mechanism.

These models have been combined into a QuickBASIC program (INEXPLC.BAS) and its PC executable form (INEXPLC.EXE). These programs, along with sample input and output files, are available from the author.

\section{ATMOSPHERIC DISPERSION EQUATIONS}

The models for close-in atmospheric dispersion are based on exact solutions to the differential equation of a convection, turbulent-diffusion model for a finite-area (semicircular) source and a point source. Details are given in Appendix A. These models assume simple gas dispersion (no chemical reactions, neutral buoyancy) with no effects of nearby structures (no building wakes or downwash). The source lies in the $Y-Z$ plane and diffusion is assumed to be restricted by solid boundaries (vertical at $X=0$ and horizontal at $Z=0$ ) to the upper-right quadrant $(X \geq 0,-\infty<Y<\infty, Z \geq 0)$. $X$ is the horizontal coordinate in the downwind direction, $Y$ is the horizontal coordinate in the crosswind direction, and $\mathrm{Z}$ is the vertical coordinate.

\section{The Region Very Close To The Release (Less Then 2 Meters Downwind)}

The semicircular source encompasses the area given by $Y^{2}+Z^{2} \leq r^{2}$. The dispersion model for this source is a relatively simple expression only along the $\mathrm{X}$-axis (the line $\mathrm{Y}=\mathrm{Z}=0$ ). Values on this line are the maximums at specific downwind locations. The equation for the model along this line is

$$
\begin{gathered}
I_{F}=\frac{2 Q}{\pi U r^{2}}\left[1-\exp \left(-\frac{r_{A}}{\left(1+s_{F}\right)}\right)+\left(\frac{r_{A}}{\left(1+s_{F}\right)}\right) \exp \left(-\frac{r_{A}}{\left(1+s_{F}\right)}\right)\right. \\
\left.-X_{A} r_{A} \exp \left(2 X_{A}\right) E_{1}\left(X_{A}\left(1+s_{F}\right)\right)\right] \\
r_{A}=\frac{r^{2}}{A_{y} A_{z}}, \quad X_{A}=\left(\frac{X}{A_{x}}\right)^{2}, \quad s_{F}=\sqrt{1+\frac{r_{A}}{X_{A}}}
\end{gathered}
$$

$I_{F}$ is the infinite-time, concentration-time integral close to a finite-area source, $\mathrm{g} \mathrm{sec} / \mathrm{m}^{3}$

$\mathrm{Q}$ is the amount of material released to the air, $\mathrm{g}$

$r$ is the effective radius of the finite-area source (area is $0.5 \pi r^{2}$ ), $m$ 
$\mathrm{U}$ is the velocity of the air carrying material from the source in the $\mathrm{X}$ direction, $\mathrm{m} / \mathrm{sec}$.

$\mathrm{X}$ is the downwind distance of the receptor from the release (positive values only), $\mathrm{m}$

$\mathrm{Y}$ is the horizontal distance of the receptor measured from the $\mathrm{X}$ axis (all values), $\mathrm{m}$

$\mathrm{Z}$ is the vertical distance of the receptor measured from the $\mathrm{X}$ axis (positive values only), $\mathrm{m}$

$A_{x}, A_{y}, A_{z}$ are dispersion parameters in the $X, Y$, and $Z$ directions, respectively, $m$

$E_{1}()$ is the exponential integral function (Abramowitz and Stegun, 1964, Pages 227 to 251).

Equation 1 is derived (see Appendix $A$ ) with the assumption that $A_{y}=A_{z}$ which is true for most cases within this very close-in region (see Equation 7). The definition of $r_{A}$ in Equation 2 is an approximation used to generalize Equation 1 for those cases where $A_{y}$ is not equal to $A_{z} . A_{x}$ is always assumed equal to $A_{y}$.

For a constant rate release over a finite duration, $\mathrm{Q}$ is replaced by $(\tau \mathrm{dQ} / \mathrm{dt})$ where $\tau$ is the duration of the release (sec) and $t$ is the time after initiating the release $(\mathrm{sec})$.

The model for a point-source applies at any location within the upper-right quadrant except right at the source where the value becomes infinite. The point-source model is

$$
\begin{aligned}
& I_{p}=\frac{Q}{\pi U A_{y} A_{2}} \sum_{j=0}^{j=1}\left[\frac{1}{s_{j}} \exp \left(-\frac{H_{j}}{\left(1+s_{j}\right)}\right)-X_{A} \exp \left(2 X_{A}\right) E_{1}\left(X_{A}\left(1+s_{j}\right)\right)\right] \\
& H_{j}=\left(\frac{Y}{A_{y}}\right)^{2}+\frac{(Z-H)^{2}+4 j Z H}{A_{z}^{2}}, \quad s_{j}=\sqrt{1+\frac{H_{j}}{X_{A}}}
\end{aligned}
$$

$I_{P}$ is the infinite-time, concentration-time integral close to a point source, $\mathrm{g} \mathrm{sec} / \mathrm{m}^{3}$

$H$ is the vertical position (positive values) of the point source measured from the $\mathrm{X}$ axis, $\mathrm{m}$

$\mathrm{j}$ is a counting variable with values 0 and 1 .

For $\mathrm{H}=0$ (ground-level source), the value of $\mathrm{I}_{\mathrm{p}}$ along the line through the source (the $\mathrm{X}$-axis) will always be larger than the corresponding $I_{F}$ value at a specific downwind $(X)$ location but the difference between the two values decreases with increasing $X$. However, the value of $I_{p}$ off the $X$-axis (the line $Y \neq 0$ and/or $Z>0$ ) may be smaller than the corresponding $I_{F}$ value. For $H>0$ (elevated source), the value of $I_{p}$ may be smaller than the corresponding $I_{F}$ value even along the line through the source $(Y=0, Z=H)$ except very close to the source. Since the finite-area model is only applicable along the $\mathrm{X}$-axis, the recommended value to use for a receptor and/or a source off this line is the smaller of $l_{F}$ and $I_{p}$. 


\section{The Region Beyond 2 Meters Downwind for Large Sources $\left(r_{4}>0.04\right)$}

Beyond $2 \mathrm{~m}$ downwind, the arguments of the exponential integral functions in Equations 1 and 3 become large enough such that the functions approach their asymptotic forms. This leads to the foliowing expressions for $I_{F}$ and $I_{p}$.

$$
\begin{aligned}
& I_{F}=\frac{2 Q}{\pi U r^{2}}\left[1-\exp \left(-\frac{r_{A}}{\left(1+s_{F}\right)}\right)\right] \\
& I_{P}=\frac{Q}{\pi U A_{y} A_{z}} \sum_{j=0}^{j=1}\left[\frac{1}{s_{j}\left(1+s_{j}\right)} \exp \left(-\frac{H_{j}}{\left(1+s_{j}\right)}\right)\right]
\end{aligned}
$$

As with Equations 1 and 3, the smaller of $I_{F}$ and $I_{P}$ should be used for a receptor and/or a source off the $\mathrm{X}$-axis.

The Region Beyond 2 Meters Downwind for Small Sources $\left(r_{n} \leq 0.04\right)$

When the ratio of source radius to downwind distance is small enough, the finite-area source becomes indistinguishable from a point source. Equation 6 is used exclusively for this situation and is identical to Equation 11 in Appendix E of ESCSET-2/R1 (1992) if $Y=Z=0$ and $s=1$. For $Y=Z=0$, $s_{j}=1.0$ for $H=0$ and is within 1 percent of 1.0 for for $H=20 \mathrm{~m}$ and $X>400 \mathrm{~m}$ at $F$ stability $(200 \mathrm{~m}$ at A stability).

\section{Recommended Dispersion Parameters}

The recommended dispersion parameters are given by Bloom, (1992) and can be expressed as

$$
\begin{array}{rlrl}
A_{y}, A_{2} & \approx 0.175 \sqrt{X} & & \text { for small } X \\
& =\frac{a X}{(1.0+b X)^{n}} \quad n=0,1 / 2,1 \quad \text { for large } X
\end{array}
$$

$\mathrm{a}, \mathrm{b}, \mathrm{n}$ are empirical coefficients in the expressions recommended by Briggs for constant-rate releases, level ground, and open-country conditions (Hanna et al, 1982, Table 4.5, Page 30).

Values for $A_{y}$ and $A_{z}$ should be computed using both of the above expressions and the larger of the two values should be used. 


\section{EXPLOSIVE RELEASES}

The analysis of explosion-induced releases involves two types of calculations: (1) estimating the amount of material that could become airborne as a result of the explosion and (2) estimating the fraction of the airborne material that is within a particle-size range that could cause adverse health effects to people inhaling the material.

\section{Amount Airborne}

The amount of material airborne due to an explosion is based on an expression given by Ayer et al (1988, Page 4.49, Equation 4.31)

$$
\begin{aligned}
F & =1.0 & & \text { for }\left(\frac{W_{T}}{W_{E}}\right)<5 \\
& =2.783\left(\frac{W_{T}}{W_{E}}\right)^{-0.6383} & & \text { for }\left(\frac{W_{T}}{W_{E}}\right) \geq 5
\end{aligned}
$$

$F$ is the fraction of material airborne

$\mathrm{W}_{\mathrm{E}}$ is the strength of the explosive expressed as grams of TNT

$\mathrm{W}_{\mathrm{T}}$ is the total weight of other material (material at risk and any inert material) involved in the explosion, $\mathrm{g}$.

\section{Particle-size Distribution of the Airborne Material}

The particle-size of the airborne material is assumed to follow a log-normal distribution with respect to mass and, consequently, the fraction of material airborne within two particle-size diameters is given by

$$
F_{R}=0.5 F\left[\operatorname{erfc}\left(\frac{\ln \left(\frac{d_{1}}{m}\right)}{\sqrt{2} \ln (g)}\right)-\operatorname{erfc}\left(\frac{\ln \left(\frac{d_{2}}{m}\right)}{\sqrt{2} \ln (g)}\right)\right]
$$

$F_{R}$ is the fraction of material airborne within particle-size diameters $d_{1}$ and $d_{2}$

$d_{1}, d_{2}$ are the particle diameters $\left(d_{2}>d_{1}\right), \mu m$

$\mathrm{m}$ is the mass median particle diameter, $\mu \mathrm{m}$

$\mathrm{g}$ is the geometric standard deviation (usually has a value of 4 )

erfc( ) is the complementary error function (Abramowitz and Stegun, 1964, Pages 295 to 329). 
If the mass median particle diameter is not specified, it may be estimated with the following expression if the material dispersed by the explosion is either a liquid, solid, or compacted powder. The expression is an empirical fit to the curve presented by Steindler and Seefeldt (1981) and is consistent with Equation 8.

$$
m=38.962\left(\frac{W_{T}}{W_{E}}\right)^{0.3617}
$$

\section{DISPERSION WITH PARTICLE DEPOSITION}

The model for dispersion with particle deposition is based on Hanna et al (1982, Pages 67 to 71) and is

$$
\begin{aligned}
& I_{D}=I_{0} \exp \left(-\sqrt{\frac{2}{\pi}}\left(\frac{v_{D}}{U}\right) G\right) \\
& G=\int_{0}^{x} \exp \left(-\frac{H^{2}}{2 A_{2}^{2}}\right) \frac{d x}{A_{2}}
\end{aligned}
$$

$I_{D}$ is the concentration-time integral including deposition, $\mathrm{g} \mathrm{sec} / \mathrm{m}^{3}$

$I_{0}$ is the concentration-time integral excluding deposition $\left(I_{F}\right.$ or $\left.I_{p}\right), g ~ s e c / m^{3}$

$v_{D}$ is a deposition velocity, $\mathrm{m} / \mathrm{sec}$

$G$ is an intermediate variable

$x$ is an integration variable.

Hanna et al (1982, Pages 69 to 71) present values of $v_{D}$ as a function of particle size and other factors. A closed-form approximation was developed for $G$ in Equation 11 and is included in the INEXPLC code. The derivation and the detailed result is given in Appendix A.

\section{Time-weighted, Average Concentration}

The time-weighted, average concentration is related to the concentration-time integral by

$$
C=\frac{I}{t_{A}} \text { for } \tau \leq t_{A} ; C=\frac{I}{\tau} \text { for } \tau>t_{A}
$$

$I$ is either $I_{F}, I_{P}$, or $I_{D}, g \mathrm{sec} / \mathrm{m}^{3}$ 
$\mathrm{C}$ is the corresponding time-weighted, average concentration, $\mathrm{g} / \mathrm{m}^{3}$

$t_{A}$ is the averaging time interval, usually taken to be 300 seconds ( 5 minutes).

\section{INEXPLC CODE}

The above equations are incorporated into a QuickBASIC code entitled INEXPLC. A listing of the code is given in Appendix B. Appendix B also contains a sample input set and the corresponding output generated by INEXPLC. An executable version of the code (INEXPLC.EXE) is availab!e from the author and should run on most IBM-compatible PC's.

The first input to the code is the name for a file to store the results. If $D$ is entered, the file name will be the default name, INSPLM.OUT. The next input requested is a title for run. The program is set up to make several runs sequentially and will continue to run until a blank title is encountered or an error is made.

The inputs following the title are (1) ISTAB, a stability index $(0=G$, through $6=A) ;(2) H$, the height of the release, $m$; (3) $R$, the effective radius of the finite-area release, $m$; (4) QT, the amount or rate of release, $\mathrm{g}$ or $\mathrm{g} / \mathrm{sec} ;(5) \mathrm{V}$, the wind speed, $\mathrm{m} / \mathrm{sec}$; and (6) DURT, the duration of the release, sec. If the duration is greater than $0, \mathrm{QT}$ is a release rate; otherwise, QT is the amount of an instantaneous release.

The next inputs are information related to the particle-size distribution. These are (1) NPCL, the number (minus 2) of particle-size classes to be considered; (2) S, the geometric standard deviation of the distribution; and (3) PSIG, the mass median particle diameter, $\mu \mathrm{m}$, of the distribution. If NPCL $\geq 0$, this is followed by three inputs for each particle-size class. The three inputs are (1) PSI, the particle size designation, $\mu \mathrm{m}$; (2) VD, the deposition velocity, $\mathrm{m} / \mathrm{sec}$; and (3) FR, the mass fraction. These inputs must be entered in order of increasing particle size. If $\mathrm{NPCL}=0$, information must be entered for one particle-size class. The program will then assume there is one class for particle sizes less than the PSI value, and another class (identified as $1000 \times$ the PSI value) for particle sizes greater than the PSI value. IF NPCL $>0$, additional classes are considered between two successive PSI input values. Thus, if NPCL $=1$ and the succesive PSI values are 10 and 100 , the three particle-size classes considered are (1) 0 to $10 \mu \mathrm{m}$, (2) 10 to $100 \mu \mathrm{m}$, and (3) greater than $100 \mu \mathrm{m}$. If a zero is entered for PSIG, it will be calculated as either (1) the sum of the products of FR and PSI for each class, or (2) from Equation 10 if there is an explosive release. If FR is zero for all of the particle-size classes, the mass fractions will be calculated from Equation 9.

If $N P C L<0$, the released material is assumed to be a gas and the values of $S$ and PSIG are ignored. Also, there are no inputs related to individual particle-size classes.

The next inputs relate to explosive releases. These are (1) TNT, the weight of explosive, expressed as $g$ TNT equivalent and (2) DIRT, the weight of inert material, g. A zero explosive weight $(T N T=0)$ implies that either there is no explosion or the effects have already been incorporated into the amount of an instantaneous release. If TNT $>0$, the release must be instantaneous and the input value of the release duration (DURT) is ignored and is reset to zero.

The final inputs are a series of down-wind $(\mathrm{X})$, cross-wind $(\mathrm{Y})$, and vertical $(\mathrm{Z})$ distances in 
meters, for which results are to be obtained. These are entered one set at a time and a zero value for $X$ signals the end of a run. The program then starts a new run with the title.

The output first displays information for all of the inputs. If values are calculated by the program (eg a zero is entered for PSIG, the mass median particle diameter), the calculated value will appear rather than the input value. Following this information is a table consisting of the input values of $\mathrm{X}, \mathrm{Y}$, and $\mathrm{Z}$ followed by the corresponding values of the time-weighted average concentrations (C in $\mathrm{mg} / \mathrm{m}^{3}$ ) and the infinite-time, concentration-time integrals (DS in $\mathrm{mg} \mathrm{s} / \mathrm{m}^{3}$ ) for each particle-size class (PSI in $\mu \mathrm{m}$ ). The concentrations and concentration-time integrals are cumulative in that each value is for all particle sizes less then the designated size.

An easy way to run several cases is to make-up an input file (eg BEOC.IN) which can be prepared using WordPrefect or any editor. All repetitive information can easily be entered this way. The program can then be run with INEXPLC.EXE by typing "INEXPLC <BEOC.IN" at the DOS prompt. The sample input in Appendix B is actually a listing of this input file while the sample output is a listing of the output file generated by BEOC.IN.

\section{REFERENCES}

Abramowitz, M., and I.A. Stegun. 1964. Handbook of Mathematical Functions, Applied Mathematical Series No. 55. National Bureau of Standards, Washington, DC.

Ayer, J.E., A.T. Clark, P. Loysen, M.Y. Ballinger, J. Mishima, P.C. Owczarski, W.S. Gregory, and B.D. Nichols. 1988. Nuclear Fuel Cycle Facility Accident Analysis Handbook. NUREG-1320, U.S. Nuclear Regulatory Commission, Office of Nuclear Material Safety and Safeguards, Washington, D.C.

Bloom, S.G. 1992. Atmuspheric Transport Analysis used in Hazard Screening Methodology, paper (92-WA/SAF-5) presented at the session on Safety Engineering and Risk Assessment (SERAD) at the Winter Annual Meeting of the American Society of Mechanical Engineers (November 8-13, 1992) in Anaheim, California. Also Y/ENG/SE-109, Martin Marietta Energy Systems, Inc., Oak Ridge, TN

Csanady, G.T. 1973. Turbulent Diffusion in the Environment, D. Reidel Publishing Co., Boston, MA.

ESCSET-2/RI (Central Safety Evaluation Team of Martin Marietta Energy Systems, Inc.), 1992. Safety Analysis Report Update Program, Hazard Screening Application Guide, ESCSET-2/RI. Martin Marietta Energy Systems, Inc., Oak Ridge, TN.

Hanna, S.R., G.A. Briggs, and R.P. Hosker, Jr. 1982. Handbook on Atmospheric Diffusion, DOE/TIC-11223, U.S. Department of Energy, Office of Energy Research, Washington, D.C.

Steindler, M.J., and W.H. Seefeldt. 1981. A Method for Estimating the Challenge to an Air Cleaning System. In Proceedings of the 16th DOE Air Cleaning Conference, ed. M.W. White, Pages 1165 to 1174, CONF-801038, Vol 2, Harvard Air Cleaning Laboratory, Boston,MA. 
APPENDIX A

DERIVATION OF EQUATIONS

FOR THE ATMOSPHERIC DISPERSION MODELS

AND DEPOSITION MODELS 


\section{ATMOSPHERIC DISPERSION MODEL}

The atmospheric dispersion model for close-in distances is based on the differential equation for three-dimensional diffusion into a medium which is flowing at a constant velocity. The differential equation is given in many references (eg, Csanady, 1973, Page 7) and, for diffusivities that have directional commonents but are otherwise constant, the equation is

$$
\frac{\partial C}{\partial t}=\sum_{i=1}^{1-3} D_{i} \frac{\partial^{2} C}{\partial x_{i}^{2}}-U \frac{\partial C}{\partial x_{1}}
$$

$\mathrm{C}$ is concentration, $\mathrm{g} / \mathrm{m}^{3}$

$I=1,2,3$ refers to the three principal directions, $X, Y, Z$, respectively

$D_{i}$ is the diffusivity in Direction $\mathrm{i}, \mathrm{m}^{2} / \mathrm{sec}$

$x_{i}$ is the distance of the receptor from the source in Direction $i, m\left(x_{1}\right.$ corresponds to $X$ in the main body of the report, $x_{2}$ corresponds to $Y$, and $x_{3}$ corresponds to $Z$ )

$\mathrm{U}$ is the velocity of the medium in the $\mathrm{X}$ direction (Direction 1 ), $\mathrm{m} / \mathrm{sec}$.

The relationship between the diffusivities and the dispersion parameters are

$$
A_{1}=\sqrt{\frac{2 D_{1} x_{1}}{U}}
$$

The initial and boundary conditions for an instantaneous point source (located at $x_{1}=0, x_{2}=h_{2}$, and $\left.x_{3}=h_{3}\right)$, and for diffusion restricted to the upper-right quadrant $\left(x_{1} \geq 0,-\infty<x_{2}<\infty, x_{3} \geq 0\right)$ are

$$
\begin{aligned}
& C=0 \text { for }\left|x_{1}\right|>0 \text { and } t=0, \\
& C \rightarrow 0 \text { for }\left|x_{1}\right| \rightarrow \infty \text { and } t>0, \quad \int_{0}^{-} d x_{1} \int_{-\infty}^{-} d x_{2} \int_{0}^{\infty} d x_{3} C=Q \text { for } t>0
\end{aligned}
$$

$h_{i}$ is the position of the source in Direction $i, m$.

The solution to Equations $\mathrm{A} 1$ and $\mathrm{A} 3$ can be expressed analytically as

$$
\begin{aligned}
C= & \frac{Q}{4 \pi t \sqrt{D_{2} D_{3}}} \exp \left(-\frac{\left(x_{2}-h_{2}\right)^{2}}{4 D_{2} t}\right) \sum_{j=0}^{j=1}\left[\exp \left(-\frac{\left(x_{3}-h_{3}\right)^{2}+4 j x_{3} h_{3}}{4 D_{3} t}\right)\right] \\
& \times\left[\frac{1}{\sqrt{\pi D_{1} t}} \exp \left(-\frac{\left(x_{1}-U t\right)^{2}}{4 D_{1} t}\right)-\frac{U}{2 D_{1}} \exp \left(\frac{U x_{1}}{D_{1}}\right) \operatorname{erfc}\left(\frac{x_{1}+U t}{\sqrt{4 D_{1} t}}\right)\right]
\end{aligned}
$$

erfc( ) is the complementary error function (Abramowitz and Stegun, 1964, Pages 295 to 329). 
The infinite-time, concentration-time integral is the integral of Equation $A 4$ from $t=0$ to $t=\infty$. The integration of the erfc term is accomplished by changing the order of integration.

$$
\begin{aligned}
& \int_{0}^{\infty} \operatorname{erfc}\left(\frac{x_{1}+U t}{\sqrt{4 D_{1} t}}\right) \exp \left(-\frac{\left(x_{2}-h_{2}\right)^{2}}{4 D_{2} t}-\frac{\left(x_{3}-h_{3}\right)^{2}+4 j x_{3} h_{3}}{4 D_{3} t}\right) \frac{U d t}{8 \pi D_{1} \sqrt{D_{2} D_{3} t}} \\
& =\int_{0}^{\infty} \int_{x_{1}}^{\infty} \exp \left(-\frac{(x+U t)^{2}}{4 D_{1} t}-\frac{\left(x_{2}-h_{2}\right)^{2}}{4 D_{2} t}-\frac{\left(x_{3}-h_{3}\right)^{2}+4 j x_{3} h_{3}}{4 D_{3} t}\right) \frac{U d x d t}{8 \sqrt{D_{2} D_{3}\left(D_{1} \pi t\right)^{3 / 2}}} \\
& =\int_{x_{1}}^{\infty} \int_{0}^{\infty} \exp \left(-\frac{(x+U t)^{2}}{4 D_{1} t}-\frac{\left(x_{2}-h_{2}\right)^{2}}{4 D_{2} t}-\frac{\left(x_{3}-h_{3}\right)^{2}+4 j x_{3} h_{3}}{4 D_{3} t}\right) \frac{U d t d x}{8 \sqrt{D_{2} D_{3}\left(D_{1} \pi t\right)^{3 / 2}}}
\end{aligned}
$$

The result is equivalent to Equations 3 and 4, with Equation $A 2$ relating $A_{i}$ to $D_{i}$, and is

$$
\begin{aligned}
& I_{P}=\frac{Q}{2 \pi x_{1} \sqrt{D_{2} D_{3}}} \sum_{j=0}^{j=1}\left[\frac{1}{p_{j}} \exp \left(-P\left(p_{j}-1\right)\right)\right. \\
& \left.-P \exp (2 P) E_{1}\left(P\left(p_{j}+1\right)\right)\right] \\
& p_{j}=\sqrt{1+\frac{D_{1}}{x_{1}^{2}}\left(\frac{\left(x_{2}-h_{2}\right)^{2}}{D_{2}}+\frac{\left(x_{3}-h_{3}\right)^{2}+4 j x_{3} h_{3}}{D_{3}}\right)}, \quad P=\frac{U x_{1}}{2 D_{1}}
\end{aligned}
$$

The result is the same for a constant rate release over a finite duration if $\tau d Q / d t$ replaces $Q$.

If $D_{2}=D_{3}=D$, Equation $A 6$ can be expressed in cylindrical coordinates $\left(x_{1}, \rho, \theta\right)$ as

$$
\begin{aligned}
& p_{j}=\sqrt{1+\frac{D_{1}}{D x_{1}^{2}}\left(\rho^{2}+s^{2}-2 \rho s \cos \left(\theta_{s}+\{2 j-1\} \theta_{\rho}\right)\right)} \\
& \rho^{2}=x_{2}^{2}+x_{3}^{2}, \quad s^{2}=h_{2}^{2}+h_{3}^{2}, \quad \theta_{\rho}=\arctan \left(\frac{x_{3}}{x_{2}}\right), \quad \theta_{s}=\arctan \left(\frac{h_{3}}{h_{2}}\right)
\end{aligned}
$$

An expression for a semicircular source can be formed by super-positioning point sources, of strength $\mathrm{Q} /\left(0.5 \pi \mathrm{r}^{2}\right)$, within the semicircular area. This is equivalent to integrating the product of $s$ and Equation $\mathrm{A} 5$, as defined with Equation $\mathrm{A} 7$, with $\mathrm{s}$ ranging from 0 to $\mathrm{r}$ and $\theta$, ranging from 0 to $\pi$. A closed-form expression of the integral can be obtained for $\rho=0$ and is equivalent to Equations 1 and 2, with Equation $A 2$ relating $A_{i}$ to $D_{i}$. The result is 


$$
\begin{gathered}
I_{F}=\frac{2 Q}{\pi U r^{2}}\left[1-\exp \left(-P\left(p_{F}-1\right)\right)+\frac{P r_{F}}{p_{F}+1} \exp \left(-P\left(p_{F}-1\right)\right)\right. \\
\left.\quad-P^{2} r_{F} \exp (2 P) E_{1}\left(P\left(p_{F}+1\right)\right)\right] \\
r_{F}=\frac{D_{1} r^{2}}{D x_{1}^{2}}, \quad p_{F}=\sqrt{1+r_{F}}
\end{gathered}
$$

\section{DEPOSITION MODEL}

The integral in Equation 11 can be evaluated in a semi-analytical manner. With $A_{2}\left(\right.$ or $A_{3}$ ) defined by Equation 7, the integral can be written as

$$
\begin{aligned}
G & =\int_{0}^{x} \frac{\exp \left(-\frac{H^{2}}{2(0.175)^{2} x}\right)}{0.175 \sqrt{x}} d x \quad \text { for } X \leq X^{*} \\
= & \int_{0}^{x \cdot} \frac{\exp \left(-\frac{H^{2}}{2(0.175)^{2} x}\right)}{0.175 \sqrt{x}} d x \\
& +\int_{x} \frac{\left(1.0+b_{3} x\right)^{m_{3}} \exp \left(-\frac{H^{2}\left(1.0+b_{3} x\right)^{2 m_{3}}}{2\left(a_{3} x\right)^{2}}\right)}{a_{3} x} d x \text { for } X>X^{*}
\end{aligned}
$$

$\mathrm{X}^{*}$ is the down-wind location where the small-distance and large-distance expressions for $A_{2}$ are equal, $\mathrm{m}$.

The expression for $\mathrm{X} \leq \mathrm{X}^{*}$ can be integrated in a closed form which is

$$
G=\frac{2 \sqrt{2} X}{H} S_{N X}\left[\exp \left(-S_{N X}^{2}\right)-\sqrt{\pi} S_{N X} \operatorname{erfc}\left(S_{N X}\right)\right], \quad S_{N X}=\frac{H}{0.175 \sqrt{2 X}}
$$

A similar expression is obtained for the first integral in the expression for $\mathrm{X}>\mathrm{X}^{*}$. The integrand of the second integral is expressed as a Taylor series in $b_{3}$ expanded about $b_{3}=0$. Three terms are sufficient for 1 percent accuracy for most cases since $b_{3}$ is small. The resulting expression for $G$ for $\mathrm{X}>\mathrm{X}^{*}$ is 


$$
\begin{aligned}
G= & \frac{2 \sqrt{2} X^{*}}{H} s_{N X}^{*}\left[\exp \left(-s_{N X}^{\cdot 2}\right)-\sqrt{\pi} s_{N X}^{*} \operatorname{erfc}\left(s_{N X}^{*}\right)\right] \\
& +\frac{\sqrt{2}}{H} \int_{X^{*}}^{x} s_{F X} \exp \left(-s_{F X}^{2}\right) d x+\frac{b_{3} n_{3}}{a_{3}} \int_{x^{*}}^{x}\left[1-2 s_{F X}^{2}\right] \exp \left(-s_{F X}^{2}\right) d x \\
& +\frac{b_{3}^{2} n_{3}}{2 a_{3}} \int_{X^{*}}^{x}\left[n_{3}-1-2\left(4 n_{3}-1\right) s_{F X}^{2}+4 n_{3} s_{F X}^{4}\right] x \exp \left(-s_{F X}^{2}\right) d x \\
s_{N X}^{*} & =\frac{H}{0.175 \sqrt{2 X^{*}}}, \quad s_{F X}=\frac{H}{\sqrt{2} a_{3} x}
\end{aligned}
$$

The above integrals can be expressed in closed form to give

$$
\begin{aligned}
& G=\frac{2 \sqrt{2} X^{*}}{H} S_{N X}^{*}\left[\exp \left(-S_{N X}^{* 2}\right)-\sqrt{\pi} S_{N X}^{*} \operatorname{erfc}\left(S_{N X}^{*}\right)\right]+\frac{0.5}{a_{3}} E_{1}\left(S_{F X}^{2}\right) \\
& -\frac{0.5}{a_{3}} E_{1}\left(S_{F X}^{* 2}\right)+\frac{b_{3} n_{3}}{a_{3}}\left[X\left(\exp \left(-S_{F X}^{2}\right)-2 \sqrt{\pi} S_{F X} \operatorname{erfc}\left(S_{F X}\right)\right)\right. \\
& \left.-X^{*}\left(\exp \left(-S_{F X}^{* 2}\right)-2 \sqrt{\pi} S_{F X}^{*} \operatorname{erfc}\left(S_{F X}^{*}\right)\right)\right] \\
& +\frac{b_{3}^{2} n_{3}}{a_{3}}\left[\left(\frac{n_{3}-1}{4}+n_{3} S_{F X}^{2}\right) X^{2} \exp \left(-S_{F X}^{2}\right)\right. \\
& \left.-\left(\frac{n_{3}-1}{4}+n_{3} S_{F X}^{* 2}\right) X^{* 2} \exp \left(-S_{F X}^{* 2}\right)\right] \\
& -\frac{3 b_{3}^{2} n_{3}\left(3 n_{3}-1\right) H^{2}}{8 a_{3}^{3}}\left(E_{1}\left(S_{F X}^{2}\right)-E_{1}\left(S_{F X}^{* 2}\right)\right) \\
& S_{F X}=\frac{H}{\sqrt{2} a_{3} X} \cdot S_{F X}^{*}=\frac{H}{\sqrt{2} a_{3} X^{*}}
\end{aligned}
$$

Equation A14 is an exact expression of Equation A10 for A and B atmospheric stability classes for which $n_{3}=0$. It is a good approximation in the range $X<10,000 \mathrm{~m}$ for $E$ and $F$ stabilities ( $n_{3}$ $=1$ and $\left.b_{3}=0.0003\right)$ and for C Stability $\left(n_{3}=1 / 2\right.$ and $\left.b_{3}=0.0002\right)$. The relative error is greater than 1 percent for D Stability $\left(n_{3}=1 / 2\right.$ and $b_{3}=0.0015$ ) and $X>1,000 \mathrm{~m}$. 
APPENDIX B

LISTING OF SAMPLE INPUT, SAMPLE OUTPUT AND THE QUICKBASIC SOURCE

FOR THE INEXPLC CODE 


\section{LISTING OF SAMPLE INPUT AND OUTPUT FOR THE INEXPLC CODE}

Input

BEOC.OUT

for $\mathrm{BeO}$ from a Circular Source

$1,10, .5,1000,1.0,0$

$1,4,100$

$10, .005,0$

$100,1,0$

100,10000

$1.0,0.0$.

5.,1.0,1.0

$10 ., 1.0,2.0$

$50 ., 2.0,10$.

$100 ., 5.0,10$.

$500 ., 5.0,10$.

$1000 ., 5.0,10$.

$0 ., 0 ., 0$.

for $\mathrm{BeO}$ from a Circular Source

$1,0, .5,100,1.0,0$

$-1,4,100$

$0,1.0$

$1.0,0.0$.

$5 ., 1.0,1.0$

$10 ., 1.0,2.0$

$50 ., 2.0,10$.

$100 ., 5.0,10$.

$500 ., 5.0,10$

$1000 ., 5.0,10$.

$0,0,0$ 
Outout

DISPERSION ESTIMATES for BeO from a circular source

$\operatorname{QT}(\mathrm{g}$ or $\mathrm{g} / \mathrm{s})=1000, \mathrm{~V}(\mathrm{~m} / \mathrm{s})=1, \operatorname{ISTAB}=1, \mathrm{H}(\mathrm{m})=10$ $R(m)=.5$, NPCL $=1, s=4$, PSIG(mic) $=100$ $\operatorname{PSI}(\mathrm{mlc})=10, \mathrm{VD}(\mathrm{m} / \mathrm{s})=.005, \mathrm{FR}=.0483604$ PSI (mic) $=100, V D(m / s)=.1, F R=.4516395$ $\operatorname{TNT}(g)=100, \operatorname{DIRT}(g)=10000, \operatorname{DURT}(s)=0$

$X(m)$

$1.000 \mathrm{E}+00$

$1.000 E+00$

1. $000 \mathrm{E}+00$

5. $000 \mathrm{E}+00$

$5.000 \mathrm{E}+00$

5. $000 \mathrm{E}+00$

1. $000 \mathrm{E}+01$

1. $000 E+01$

$1.000 E+01$

5. $000 E+01$

5. $000 E+01$

5. $000 E+01$

1. $000 \mathrm{E}+02$

1. $000 E+02$

1. $000 \mathrm{E}+02$

5. $000 \mathrm{E}+02$

5. $000 \mathrm{E}+02$

5. $000 \mathrm{E}+02$

1. $000 \mathrm{E}+03$

1. $000 \mathrm{E}+03$

1. $000 \mathrm{E}+03$
$Y(m)$

$0.000 \mathrm{E}+00$

$0.000 E+00$

$0.000 E+00$

1. $000 \mathrm{E}+00$

$1.000 \mathrm{E}+00$

$1.000 E+00$

1. $000 E+00$

$1.000 E+00$

1. $000 E+00$

2. $000 E+00$

2. $000 E+00$

2. $000 E+00$

5. $000 E+00$

5. $000 \mathrm{E}+00$

5. $000 E+00$

5. $000 E+00$

5. $000 E+00$

5. $000 \mathrm{E}+00$

5. $000 E+00$

5. $000 \mathrm{E}+00$

5. $000 \mathrm{E}+00$
$Z(m)$

$0.000 E+00$

$0.000 E+00$

$0.000 E+00$

1. $000 \mathrm{E}+00$

$1.000 \mathrm{E}+00$

1. $000 \mathrm{E}+00$

2. $000 \mathrm{E}+00$

2. $000 E+00$

2. $000 E+00$

1. $000 E+01$

$1.000 E+01$

1. $000 \mathrm{E}+01$

$1.000 E+01$

1. $000 E+01$

1. $000 E+01$

$1.000 E+01$

1. $000 E+01$

$1.000 E+01$

1. $000 E+01$

1. $000 E+01$

$1.000 E+01$ $\mathrm{c}(\mathrm{mg} / \mathrm{m} 3)$

$0.000 \mathrm{E}+00$

$0.000 E+00$

$0.000 E+00$

$0.000 E+00$

$0.000 \mathrm{E}+00$

$0.000 E+00$

$3.546 \mathrm{E}-40$

$3.666 \mathrm{E}-39$

$7.332 E-39$

8.701E-01

8. $995 E+00$

1. 799E+0:

2. 315E-01

$2.393 E+00$

$4.786 \mathrm{E}+00$

2. 492E-02

1. $508 \mathrm{E}-01$

2. $902 E-01$

8.187 $8-03$

1.265E-02

1. $760 \mathrm{E}-02$
$\mathrm{DS}(\mathrm{mg} s / \mathrm{m} 3)$ PSI (mic)

$0.000 \mathrm{E}+00$ 1.000E+01

$0.000 E+00$

$0.000 E+00$

$0.000 E+00$

$0.000 \mathrm{E}+00$

$0.000 E+00$

$1.064 \mathrm{E}-37$

1. $100 \mathrm{E}-36$

$2.200 E-36$

2. $610 \mathrm{E}+02$

2. $699 \mathrm{E}+03$

$5.397 \mathrm{E}+03$

$6.944 \mathrm{E}+01$

$7.179 \mathrm{E}+02$

$1.436 \mathrm{E}+03$

$7.475 \mathrm{E}+00$

$4.525 \mathrm{E}+01$

8.707E+01

$2.456 \mathrm{E}+00$

$3.796 \mathrm{E}+00$

$5.279 \mathrm{E}+00$
$1.000 \mathrm{E}+02$

$1.000 \mathrm{E}+05$

$1.000 \mathrm{E}+01$

$1.000 \mathrm{E}+02$

$1.000 E+05$

$1.000 E+01$

1. $000 E+02$

1. $000 E+05$

1. $000 \mathrm{E}+01$

$1.000 \mathrm{E}+02$

$1.000 E+05$

1. $000 E+01$

1. $000 \mathrm{E}+02$

$1.000 \mathrm{E}+05$

1. $000 \mathrm{E}+01$

1. $000 \mathrm{E}+02$

$1.000 \mathrm{E}+05$

$1.000 \mathrm{E}+01$

$1.000 \mathrm{E}+02$

1. $000 \mathrm{E}+05$

DISPERSION ESTIMATES for BeO from a circular source

$$
\begin{aligned}
& \operatorname{QT}(\mathrm{g} \text { or } \mathrm{g} / \mathrm{s})=100, \mathrm{~V}(\mathrm{~m} / \mathrm{s})=1, \operatorname{ISTAB}=1, \mathrm{H}(\mathrm{m})=0 \\
& R(m)=.5, N P C L=-1, S=4, \text { PSIG }(\mathrm{mic})=100 \\
& \operatorname{TNT}(g)=0, \operatorname{DIRT}(g)=1, \operatorname{DURT}(s)=0
\end{aligned}
$$

$X(m)$

1.000E+00

5. $000 \mathrm{E}+00$

1. $000 \mathrm{E}+01$

5. $000 \mathrm{E}+01$

1. $000 \mathrm{E}+02$

5. $000 \mathrm{E}+02$

1. $000 \mathrm{E}+03$
$Y(m)$

$0.000 E+00$

$1.000 \mathrm{E}+00$

1. $000 \mathrm{E}+00$

2. $000 \mathrm{E}+00$

$5.000 E+00$

$5.000 \mathrm{E}+00$

5. $000 E+00$ $z(m)$

$0.000 E+00$

1. $000 \mathrm{E}+00$

2. $000 E+00$

1. $000 \mathrm{E}+01$

$1.000 \mathrm{E}+01$

1. $000 \mathrm{E}+01$

1. $000 \mathrm{E}+01$
$\mathrm{C}(\mathrm{mg} / \mathrm{m} 3)$

8. $318 \mathrm{E}+02$

$1.081 \mathrm{E}+00$

1. 051E-01

3. 651E-13

$6.768 \mathrm{E}-07$

2. $687 \mathrm{E}-01$

1. $610 \mathrm{E}-01$
DS (mg $s / m 3$ ) PSI (mic)

2.495E+05 0.000E+00

$3.243 E+02$

$3.154 \mathrm{E}+01$

$1.095 \mathrm{E}-10$

2.030E-04

$8.061 E+01$

$4.830 \mathrm{E}+01$
$0.000 E+00$

$0.000 E+00$

$0.000 E+00$

$0.000 E+00$

$0.000 E+00$

$0.000 E+00$ 
DECLARE FUNCTION E1! (X!)

DECLARE SUB ERFC $(X, F, G)$

DIM SIGCF(20), FR(6), VD(6), PSI(6)

DATA $0.0096,0.016,0.03,0.06,0.08,0.12,0.20$

DATA $0.0003,0.0003,0.0003,0.0015,0.0002,0.0,0.0$

DATA $0.02666667,0.04,0.06,0.08,0.11,0.16,0.22$

- Put coefficients for sigma values into the SIGCF array.

FOR N\% $=0$ TO 20

READ SIGCF(N\%)

NEXT N\%

- Input name for file to store results. If D, file name is INSPLM.OUT.

INPUT "OUTPUT FILE NAME FOR RESULTS (D = INSPLM.OUT) "; FILENAMS

IF FILENAM\$ $=$ " " THEN FILENAM $\$=$ "INSPLM.OUT"

OPEN "O", \#I, FILENAM\$

- Input title for run. Exit on blank title.

10 INPUT "INPUT TITLE FOR RUN "; TITLE\$

IF TITLES = DUM\$ THEN END

- Input stability index $(0=G, 6=A)$, height of release, effective radius of

- the release, amount or rate of release, wind speed, and duration of release.

- If the duration is greater than 0, QT is a release rate; otherwise. OT is an

- instantaneous release.

INPUT "INPUT ISTAB, H, R, QT, V, DUR ", ISTAB\%, H, R, QT, V, DURT

- Select coefficients for sigma values appropriate for stability index.

$A Z=$ SIGCF(ISTAB\%)

$B Z=$ SIGCF(ISTAB\% + 7)

$A Y=\operatorname{SIGCF}(I S T A B \%+14)$

- Input information related to the particle-size distribution. If $\mathrm{NPCL}<0$,

- there are no particles (all gas) and no deposition.

INPUT "INPUT NPCL, S, PSIG ", NPCL\%, S, PSIG

NPCL $1 \%=$ NPCL $\%+1:$ TEST $1 \%=0:$ TEST2 $\%=0: Q=0 !:$ PSIE $=0 !$

IF NPCL $\%>-1$ THEN

FOR N\% $=0$ TO NPCL\%

- Input particle size (increasing order), deposition velocity and fraction.

INPUT "INPUT PSI, VD, FR ", PSI(N\%), VD(N\%), FR(N\%)

IF $\mathrm{VD}(\mathrm{N} \%)>0$ ! THEN TEST $1 \%=1$

IF FR(N\%) > 0! THEN TEST2\% $=1$

$Q=Q+F R(N \%)$

$\mathrm{PSIE}=\mathrm{PSIE}+\mathrm{FR}(\mathrm{N} \%) * \mathrm{PSI}(\mathrm{N} \%)$

NEXT N\%

$\mathrm{VD}(\mathrm{NPCL} 1 \%)=\mathrm{VD}(\mathrm{NPCL} \%)$

$\operatorname{PSI}($ NPCL. $1 \%)=1000 ! * \operatorname{PSI}($ NPCL \%)

PSIE $=$ PSIE + FR(NPCL1\%) * PSI (NPCL\%) 


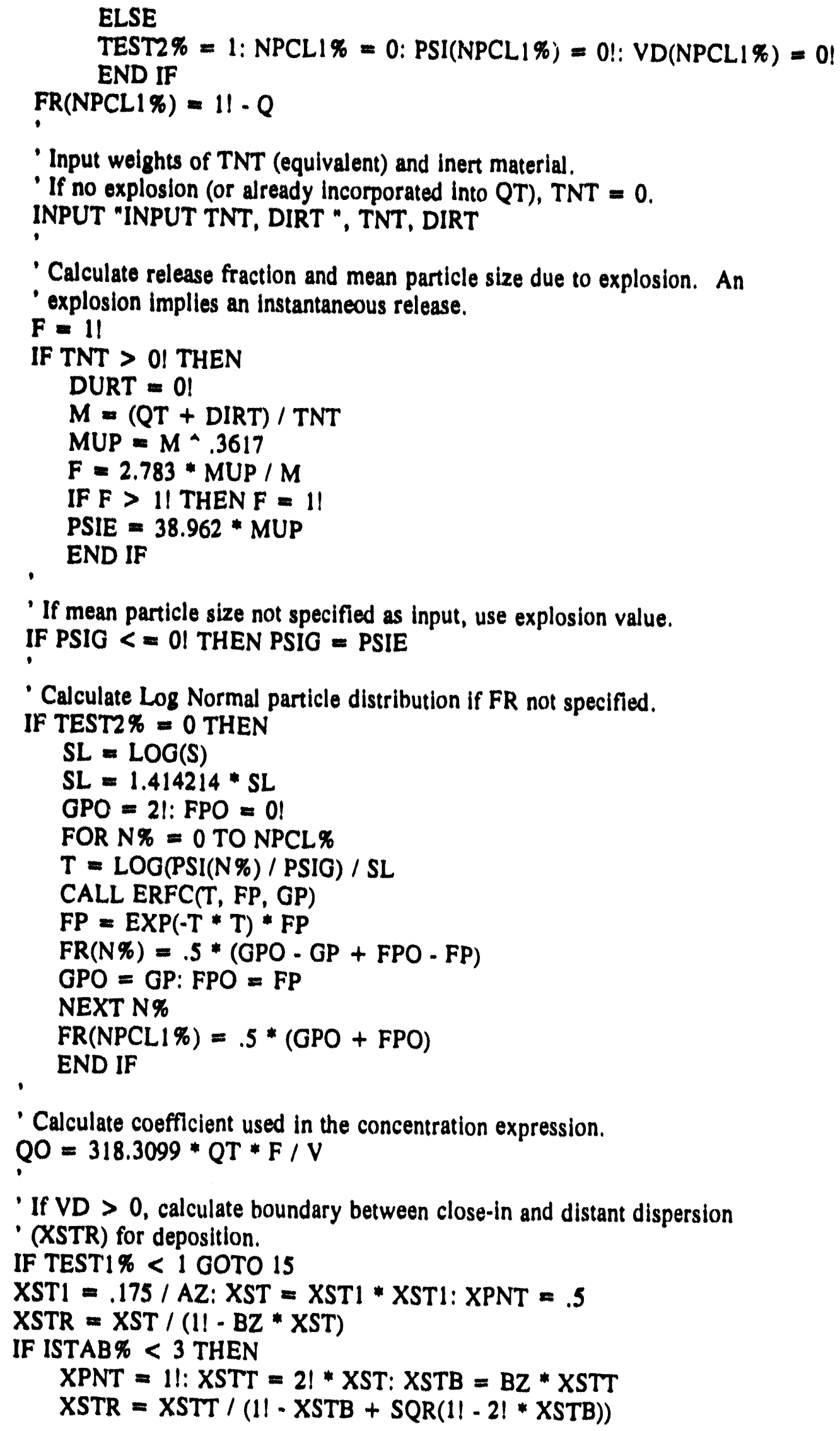

- Calculate release fraction and mean particle size due to explosion. An

- explosion implies an instantaneous release.

$F=11$

IF TNT > 0! THEN

DURT $=0$ !

$M=(Q T+D I R T) / T N T$

MUP $=M^{\wedge} .3617$

$F=2.783 *$ MUP / M

IF $F>11$ THEN $F=11$

PSIE $=38.962 *$ MUP

END IF

' If mean particle size not specified as input, use explosion value.

IF PSIG $<=0$ ! THEN PSIG = PSIE

- Calculate Log Normal particle distribution if FR not specified.

IF TEST $2 \%=0$ THEN

$S L=\operatorname{LOG}(S)$

$S L=1.414214 * S L$

$\mathrm{GPO}=2$ !: $\mathrm{FPO}=0$ !

FOR N\% $=0$ TO NPCL\%

$T=L O G(P S I(N \%) / P S I G) / S L$

CALL ERFC(T, FP, GP)

$F P=\operatorname{EXP}(-T * T) * F P$

$F R(N \%)=.5 *(G P O-G P+F P O-F P)$

$G P O=G P: F P O=F P$

NEXT N\%

FR(NPCL1\%) $=.5 *(G P O+F P O)$

END IF

- Calculate coefficient used in the concentration expression.

$\mathrm{QO}=318.3099 * \mathrm{QT} * \mathrm{~F} / \mathrm{V}$

- If VD > 0 , calculate boundary between close-in and distant dispersion

- (XSTR) for deposition.

IF TEST $1 \%<1$ GOTO 15

XST1 $=.175 / \mathrm{AZ}: \mathrm{XST}=\mathrm{XST1} * \mathrm{XST1}: \mathrm{XPNT}=.5$

$\mathrm{XSTR}=\mathrm{XST} /(1 !-\mathrm{BZ} * \mathrm{XST})$

IF ISTAB\% $<3$ THEN

XPNT $=1 !:$ XSTT $=2 ! * X S T: X S T B=B Z * X S T T$

$\mathrm{XSTR}=\mathrm{XSTT} /(1 ! \cdot \mathrm{XSTB}+\mathrm{SQR}(1 !-2 ! * \mathrm{XSTB}))$ 
END IF

IF ISTAB\% $>4$ THEN XPNT $=0$ !

SQXSTR $=2 ! *$ SQR(XSTR) $/$ XST $1: B Z N=B Z *$ XPNT: XPNI $=$ XPNT -11

- Calculate values of functions at XSTR used in deposition calculations.

IF $\mathrm{H}>0$ I THEN

$E 1 A=.5 *(\mathrm{H} / .175) \wedge 2: H O A 2=(\mathrm{H} / \mathrm{AZ})^{\wedge} 2$

$\mathrm{BZNB}=.5 * \mathrm{BZN} * \mathrm{BZ}: \mathrm{XPN} 3=3 ! * \mathrm{XPNT}-1 !$

SNS2 = E1A / XSTR: SFS2 = .5* HOA2 / (XSTR * XSTR)

SNS = SQR(SNS2): SFS = SQR(SFS2)

CALL ERFC(SNS, PN, GN): CALL ERFC(SFS, PF, GF)

EXPN = EXP(-SNS2): EXPF = EXP(-SFS2): E1F = El(SFS2)

E0Q $=$ SQXSTR * EXPN * $(1 !-1.772454 *$ SNS * PN $) \cdot .5 *$ EIF

$E 1 Q=-B Z N * X S T R * \operatorname{EXPF} *(11-3.544908 * S F S * P F)$

$E 2 Q=-B Z N B * \operatorname{EXPF} *(.5 * X P N 1 * X S T R * X S T R+X P N T * H O A 2)$

$\mathrm{E} 2 \mathrm{Q}=\mathrm{E} 2 \mathrm{Q}+.75 * \mathrm{BZNB} * \mathrm{XPN3} * \mathrm{HOA}_{2} * \mathrm{E} 1 \mathrm{~F}$

END IF

'Setup table headings for output.

15 PRINT \#1, DUMS

PRINT \#1, DUMS

PRINT "1, " DISPERSION ESTIMATES "; TITLES

PRINT \#1, DUMS

PRINT "1, " QT(g or g/s) = "; QT; ", V(m/s) = "; V;

PRINT "1, ", ISTAB = "; ISTAB\%; ", H(m) $=" ; H$

PRINT "I, " $R(m)=$ "; $R ;$ ", NPCL = "; NPCL\%; ", $S=$ "; $S$;

PRINT \#I, "PSIG(mic) = "; PSIG

FOR N\% $=0$ TO NPCL\%

PRINT $1, "$ PSI(mic) = "; PSI(N\%); ", VD(m/s) = "; VD(N\%); ", FR = "; FR(N\%)

NEXT N\%

PRINT "1," TNT(g) = "; TNT; ", DIRT(g) = "; DIRT; ", DURT(s) = "; DURT

PRINT \#1, DUMS

PRINT \#1, USING "II"; DUM\$;

PRINT \#1, USING "I I"; "X(m)"; "Y(m)"; "Z(m)"; "C(mg/m3)";

PRINT \#I, USING "I I"; "DS(mg s/m3)"; "PSI(mic)"

- Input $X, Y$, and $Z$ values. Reset title, etc for $X<=0$.

20 INPUT "INPUT XT, Y, Z ", XT, Y, Z

IF XT $<=0$ ! GOTO 10

$X T 2=X T \wedge 2$

DUR $=$ DURT -

- Calculate dispersion coefficients (Sigma values).

SIGY $=A Y * X T / S Q R(1 !+.0001 * X T)$

IF ISTAB\% > 4 THEN SIGZ $=A Z * X T$ : GOTO 30

IF ISTAB\% < 3 THEN SIGZ = AZ *XT / $(1 !+B Z * X T)$ : GOTO 30

SIGZ $=A Z * X T / S Q R(1 !+B Z * X T)$

$30 \quad S Y=.175 * \operatorname{SQR}(X T)$

IF SIGZ < SY THEN SIGZ = SY

IF SIGY < SY THEN SIGY $=$ SY 
- Calculate factor for particle deposition if VD > 0 .

IF TEST1\% < 1 GOTO 35

IF $H<=0$ ! THEN

IF XT < XSTR THEN

$G 0=\operatorname{SQR}(X T) * 2 ! / X S T 1: G 1=0$ !: $G 2=0$ !

ELSE

GO = LOG XT / XSTR + SQXSTR: GI = BZN * (XT - XSTR)

G2 $=01 * \mathrm{BZ} * .25 * \mathrm{XPN} 1 *(\mathrm{XT}+\mathrm{XSTR})$

END IF

ELSE

IF XT $<$ XSTR THEN

SN2 $=E 1 A / X T: S N=S Q R(S N 2)$

CALL ERFC(SN, PN, GN): EXPN = EXP(-SN2)

GO $=21 * \operatorname{EXPN} * \operatorname{SQR}(X T) / X S T I *(1 !-1.772454 * S N * P N)$

$G 1=0 !: G 2=0$ !

ELSE

$S F 2=.5 * H O A 2 / X T 2: S H=S Q R(S F 2)$

CALL ERFC(SF, PF, GF): $\operatorname{EXPF}=\operatorname{EXP}(-S F 2): E 1 F=\operatorname{El}(S F 2)$

$\mathrm{GO}=.5 * \mathrm{E} I \mathrm{~F}+\mathrm{EOQ}$

OI $=\mathrm{BZN} * \mathrm{XT} * \mathrm{EXPF} *(11-3.544908 * \mathrm{SF} * \mathrm{PF})+\mathrm{EIQ}$

G2 $=\mathrm{BZNB} * \operatorname{EXPF} *(.5 * \mathrm{XPN} 1 * \mathrm{XT} * \mathrm{XT}+\mathrm{XPNT} * \mathrm{HOA2})$

G2 $=02-.75 * \mathrm{BZNB} * \mathrm{XPN} 3 * \mathrm{HOA2} * \mathrm{E} 1 \mathrm{~F}+\mathrm{E} 2 \mathrm{Q}$

END IF

END IF

$\mathbf{G}=\mathbf{G O}+\mathbf{G 1}+\mathbf{G 2}$

GOAZ $=-.7978846 / V * G / A Z$

- Calculate concentration from either a point or a circular source.

$35 \mathrm{HA}=(\mathrm{Y} / \mathrm{SIGY})^{\wedge} 2+((\mathrm{H}-\mathrm{Z}) / \mathrm{SIGZ}) \wedge 2$

SIGYZ $=$ SIGY $*$ SIGZ

$X A=(X T / S I G Y) \wedge 2$

$D S=Q O / S I G Y Z$

- Point source.

DSP $=0$ !

FOR N\% $=0$ TO 1

$\mathrm{TMP}=\mathrm{SQR}(1 !+\mathrm{HA} / \mathrm{XA})$

TMPPI $=1 !+$ TMP

EXHA $=$ EXP(-HA / TMPPI)

IF XT $<2$ ! THEN

- Very small XT.

$\operatorname{EXXA}=\operatorname{EXP}(2 ! * X A)$

DSP $=$ DSP + EXHA / TMP - XA * EXXA * El(TMPPI * XA)

ELSE

- Larger XT.

DSP $=$ DSP + EXHA / TMP / TMPPI

END IF 
$H A=H A+4 ! * Z * H / S^{\prime} Z^{\wedge} 2$

NEXT N\%

$D S P=D S P * D S$

- For small distances compared to the radius of the source, use the smaller of

- the concentration due to a point or circular source.

$R A=R \wedge 2 /$ SIGYZ

IF $\mathrm{RA}>.04 \mathrm{THEN}$

- Circular source.

$T M P I=S Q R(11+R A \mid X A)$

TMPIPI $=11+$ TMPI

RATMP = RA / TMPIPI

EXRA = EXP(-RATMP)

IF XT $<2$ ! THEN

-

' Very small XT.

$$
\text { DSC }=11 \cdot \text { EXRA + RATMP *EXRA - XA * RA * EXXA * EI(TMPIPI* XA) }
$$

ELSE

- Larger XT.

DSC $=11 \cdot$ EXRA

END IF

$D S C=2 ! * D S C * D S / R A$

IF DSC $<$ DSP THEN DSP = DSC

END IF

IF DUR $>0$ ! THEN

DSS = DSP * DUR

IF DUR < 300! THEN C = DSS / 300! ELSE C $=$ DSP

ELSE

DSS $=$ DSP

$C=$ DSS / 300 !

END IF

$Q=0 !$

FOR N\% $=0$ TO NPCL. $1 \%$

IF $\mathrm{VD}(\mathrm{N} \%)=0$ ! THEN

$Q=Q+F R(N \%)$

EL.SE

$Q=Q+F R(N \%) * \operatorname{EXP}(G O A Z * V D(N \%))$

END IF

DSSS $=$ DSS $* Q: C S=C * Q$

PRINT \#1, USING " \#\#,\#H\#AaA"; XT; Y; Z; CS; DSSS; PSI(N\%)

NEXT N\%

GOTO 20

FUNCTION EI (XX)

Calculates the exponential integral function E1 using Equations 5.1.53

- and 5.1.54, Page 231 in M. Abramowitz and I.A. Stegun (eds), "Handbook

- of Mathematical Functions", Applied Mathematics Series 55, National 
- Bureau of Standards, June, 1964.

$\mathbf{X}=\mathbf{X X}$

IF $X<\|$ THEN

$E=((1.07857 * X \cdot 9.76004) * X / 101+5.519968) * X / 101$

$E=((E \cdot 2.499106) * X / 101+.9999919) * X \cdot .5772157 \cdot L O O(X)$

ELSE

$E=(X+2.33473+.250621 / X) /(X+3.330657+1.681534 / X)$

$E=E / X * \operatorname{EXP}(\cdot X)$

END IF

$\mathbf{E} 1=\mathbf{E}$

END FUNCTION

SUB ERFC $(X, F, G)$

- Calculates $F$ and $G$ in the expression $\operatorname{ERFC}(X)=O+\operatorname{EXP}\left(\cdot X^{\wedge} 2\right)^{\star} F(X)$

- for all real $X$.

$G=2.0$ for $X<0.0$ and $G=0.0$ otherwise.

- F is calculated to 6 slenificant figures using a polynomial based

- on the Chebyshev approximation presented by M.M. Shepherd and

' J.G. Laframboise, Math Comp, V36, No 153, p 249-253 (1981).

$X X=A B S(X)$

$T=(X X-3.75) /(X X+3.75)$

$P=((3.9424 E-04 * T+1.05984 E-03) * T \cdot 9.83936 E-03) * T+2.902502 E-02$

$\mathrm{F}=(((\mathrm{P} * \mathrm{~T} \cdot .0586512) * \mathrm{~T}+9.202154 \mathrm{E}-02) * \mathrm{~T} \cdot .1088129) * \mathrm{~T}$

$P=(((P+8.232646 \mathrm{E}-02) * T+3.58616 \mathrm{E}-03) * T \cdot .1402431) * T+1.237513$

$F=P /(1 !+2 ! * X X)$

IF $X<0$ ! THEN $F=-F: G=2 !:$ ELSE $G=0$ !

END SUB 

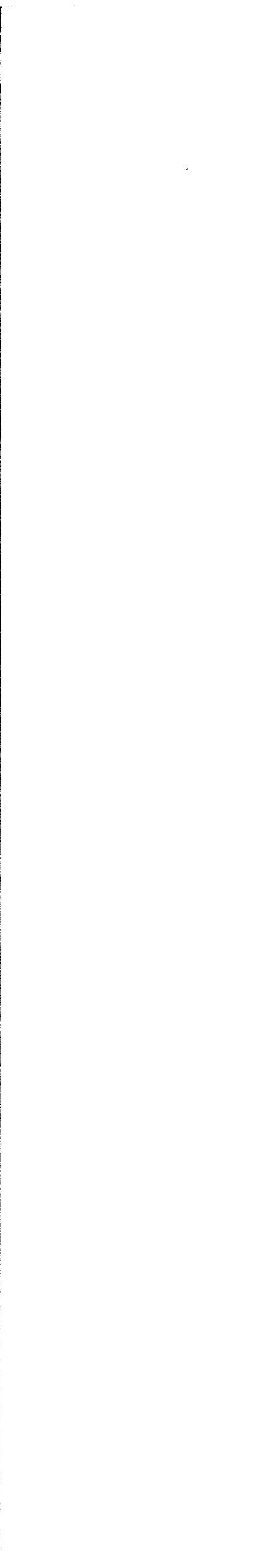

-
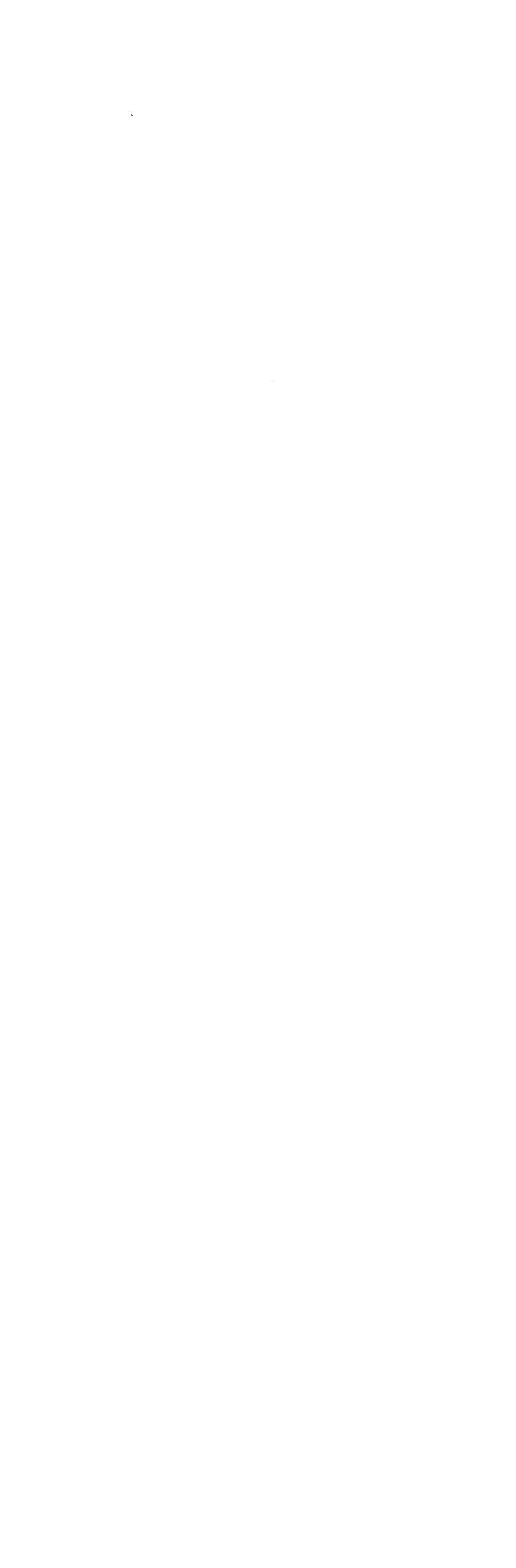